\title{
Cation Release from Geothermal Reservoir Rocks
}

\author{
Belshaw GE ${ }^{1}$, AZIS $\mathrm{H}^{2}$,SAPIIE B ${ }^{3}$, MUlJadi B ${ }^{4}$, \\ VANDEGINSTE $\mathrm{V}^{1}$ \\ ${ }^{1}$ School of Chemistry, University of Nottingham \\ (contact: grace.belshaw@nottingham.ac.uk) \\ ${ }^{2}$ PT Supreme Energy, Jakarta, Indonesia \\ ${ }^{3}$ Institut Teknologi Bandung, Indonesia \\ ${ }^{4}$ Faculty of Engineering, University of Nottingham
}

Geothermal energy is often located in areas of volcanic acitivity, which can lead to the release of $\mathrm{CO}_{2}$ during the energy extraction process. Previous field scale studies have demonstrated success in dissolving $\mathrm{CO}_{2}$ in water and reinjecting this into the subsurface, primarily in basaltic rock systems, for carbon sequestration via carbonate mineral formation $[1,2] . \mathrm{CO}_{2}$ trapping in alternative volcanic rocks is less well constrained. The present study uses batch reactor experiments at $100^{\circ} \mathrm{C}$ and injected $\mathrm{CO}_{2}$ at increased pressure to investigate dissolution/precipitation reactions with andesitic rocks from active geothermal wells. The solutions and solids are analysed pre and post experiment to assess divalent cation release. The experimental fluid compositions are designed to simulate that expected from a fluid injected into a geothermal reservoir, both near and far from the injection point. The aim of the study is to examine the rate and extent of divalent cation release from dissolution reactions with andesitic rocks under $\mathrm{CO}_{2}$ injection conditions and whether the formation of carbonate minerals is therefore expected in andesitic geothermal reservoirs.

The obtained Indonesian volcanic core samples have a mineralogy which includes high concentrations of feldspars with quartz, alongside chlorite and minor anhydrite, zeolite and clay fractions, determined using PXRD, XRF, Optical Microscopy and Microprobe analysis. The solutions are examined with ICP-OES and indicate that $\mathrm{Ca}^{2+}$ ions with minor amounts of $\mathrm{Mg}^{2+}$ ions are released into the solutions via feldspar dissolution reactions within the 15 day reaction timescale. The amounts of divalent cations released (predominatly of $\mathrm{Ca}^{2+}$ ) from these andesitic samples are compared to results from basaltic samples used in previous studies, to predict whether andesitic rocks will be equally suitable for carbon sequetsration via mineral formation relative to basaltic samples.

[1] Gíslason et al. (2018), Energy Procedia, 146, 103-114

[2] McGrail et al. (2011), Energy Procedia, 4, 5653-5660 